\title{
Announcement of a Cooperative Research and Development Agreement (CRADA) Opportunity for a Large-Scale Blade Test Facility Partnership
}

\section{Summary}

The U.S. Department of Energy's (DOE's) National Renewable Energy Laboratory (NREL) is seeking government, private, or non-profit partners to design, construct, and assist in operating one or more wind turbine blade test facilities capable of testing blades up to at least $70 \mathrm{~m}(230 \mathrm{ft})$ in length. DOE/NREL encourages interested parties to respond to this Cooperative Research and Development Agreement (CRADA) announcement with a proposal by October 2, 2006.

NREL is the nation's primary laboratory for renewable energy and energy efficiency research and development. The DOE Office of Energy Efficiency and Renewable Energy provides the majority of NREL's funding. The DOE/NREL motivation for this partnership is to support the U.S. wind industry's development and the deployment of large land-based and offshore wind turbines by providing testing capabilities of sufficient size and availability at a reasonable cost to the users. Blade testing is required to meet wind turbine design standards, reduce machine cost, and reduce the technical and financial risk of deploying mass-produced

\section{Table 1: Example CRADA Tasks and Schedule}

CRADA Application Deadline:

Oct. 2, 2006

CRADA Negotiation:

Oct. 2006 - Dec. 2006

CRADA Phase I:

Jan. 2007 - July 2007

- Business plan

— market study

— revenue analysis

- facility survey

- Conceptual facility design

- Establish use agreement

- Progress review meeting

- "Go/no go" decision

CRADA Phase II:

July 2007-July 2009

- Detailed facility design

- Purchase capital equipment

- Facility construction

- Commissioning.

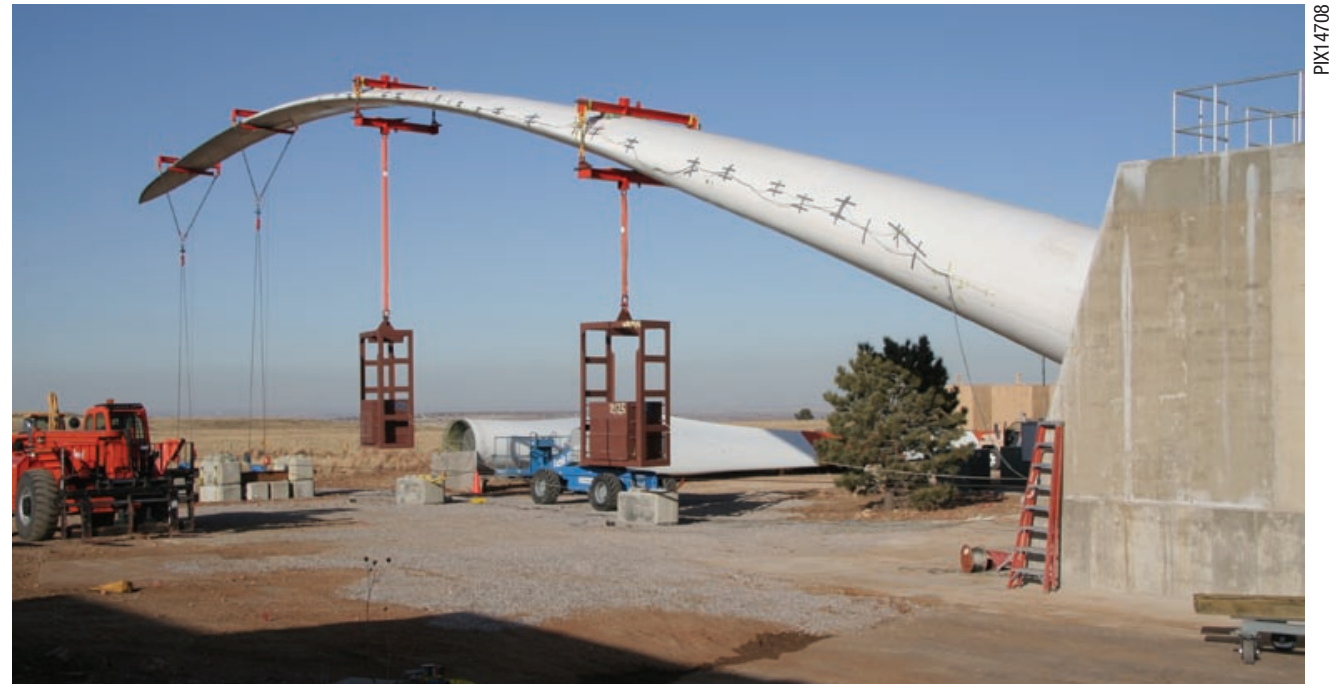

wind turbine models. NREL operates the only blade test facility in North America capable of performing full-scale testing of megawatt-scale wind turbine blades. Rapid growth in wind turbine size over the past two decades has outstripped the capabilities of this blade test facility, leaving the U.S. wind industry without a suitable means of testing blades for large land-based and offshore turbines.

The necessary contributions for a blade test facility can be summarized into six key components: land, building, test stand, test equipment, facility staff, and commitments to testing. Preliminary estimates indicate the capital costs for a 70-m facility with two test stands are approximately $\$ 5$ million (assuming the building is leased rather than purchased). Although DOE funding in future years is not certain, budget allocation for this facility has been planned. The DOE Wind Program intends to contribute capital contributions up to $\$ 2$ million, provide NREL staff and expertise to help develop and operate the facility, and license the NREL blade resonance fatigue testing tech- nology. A CRADA is an agreement designed to enable collaborations between government laboratories and industry partners. It is not a grant, and no funds are transferred from the laboratory to the partner or partners*. A use agreement will be established to outline the respective rights of the parties to the facility.

The time until commissioning of the facility is highly dependent on the availability of existing buildings suitable for housing a test facility and DOE funding constraints. The majority of the DOE funding for the partnership is anticipated to become available in FY08. An approximate schedule is listed in Table 1 based on this assumption. The schedule assumes a phased approach with a "go/no go" decision point to reduce the risk of project uncertainties. Other arrangements and schedules will be considered.

\section{Blade Test Facility Requirements}

Due to the considerable size and forces associated with large blade testing, a blade test facility has a number of unique requirements. The critical requirements are summarized below and explained in more detail in the NREL technical report The Necessity and Requirements of a Collaborative Effort

\footnotetext{
* The NREL CRADA model agreement terms and conditions and NREL technical report on the necessity and requirements of a collaborative effort can be accessed at www.nrel.gov/ wind/bladecrada.html.
} 
to Develop a Large Wind Turbine Blade Test Facility in North America.

- Self-sustaining financial operation: A self-sustaining business model is desirable to reduce partner commitments and ensure the long-term survival of the test facility. To obtain self-sufficiency, the facility must provide enough revenue to operate and maintain the facility (staff compensation, facility maintenance, utilities, etc.).

- A 70-m blade capacity: The facility should be capable of accredited staticand fatigue-testing of blades up to at least $70 \mathrm{~m}$ in length. A 70-m blade corresponds roughly to a 7-MW machine and will enable testing of all wind turbines under development.

- Transportation: The facility must be capable of shipping, receiving, and storing blades up to at least $70 \mathrm{~m}$ in length and more than $6 \mathrm{~m}(20 \mathrm{ft})$ wide. It is anticipated that future offshore wind turbine designs will be manufactured and installed near ports to overcome land-based length and height transportation restrictions. Thus, port access or other unobstructed access will be necessary to ensure offshore blades can be transported to the facility.

\section{Proposal Preparation}

The CRADA proposal must be submitted by 4:00 PM Mountain Time, October 2, 2006. CRADA proposals submitted thereafter may be considered if a suitable CRADA collaborator is not selected from among the timely responses. Final negotiations of CRADA agreements and terms and conditions will be completed after initial discussions have concluded. The proposal and inquiries should be directed to:

Jason Cotrell
National Renewable Energy Laboratory
MS3811
1617 Cole Blvd.
Golden, Colorado 80401-3393
303-384-7056
jason_cotrell@nrel.gov

If necessary, new information regarding this CRADA announcement will be posted at www.nrel.gov/wind/bladecrada.

Proposals should be limited to fewer than 10 pages and should include the following components (if applicable):

\section{Partner description}

- Identification of partners and a description of their qualifications, experience, contributions to the partnership, and letters of commitment
- Delineation of expected DOE resources.

\section{Facility description}

- Proposed location and specifications for the facility (such as the number of test stands, blade size capacity, building dimensions, transportation routes, method of testing accreditation, etc.)

- Résumés of key staff and proposal for permanent staffing positions.

\section{Business plan}

- Business model outline showing funding sources during construction and during operation

- Preliminary cash flow analysis showing top level expenses and revenue streams for first few years

- Schedule of key milestones, including projected start of construction/operation

- Operating model, including discussion of partner use rights and discussion of provisions to allow equitable access and intellectual property protection to wind industry members outside the partnership with disclosure of any anticipated restrictions

- Discussion of any expansion opportunities for longer blades, additional test stands, or other wind turbine testing capabilities

- Details regarding disposition of equipment, test stand, and facility after completion of the CRADA.

Although there are many possible ownership and operating structures for a blade test facility partnership, complications associated with co-owning government property should be avoided. For example, in addition to possibly providing staff for the facility, the DOE/NREL contribution could entail equipment (e.g., blade moving and positioning equipment, test hardware, hydraulic systems, instrumentation) or a commitment to lease/construct the building and test stand.

\section{Proposal Evaluation}

Equipment loan and expenditure of all funds are subject to the approval of the DOE. Selection of a CRADA offering will be solely at the discretion of NREL. The primary criteria used to evaluate submissions are:

1. The overall likelihood that the business plan will expeditiously result in a blade test facility as determined by factors such as the operating model, applicant qualifications, accreditation plans, letters of commitment, facility expansion opportunities, and the amount of non-DOE resources and funds to develop the blade test facility

2. The degree to which the proposed facility provides equitable access rights and intellectual property protection to wind industry members outside the partnership.
National Renewable Energy Laboratory 1617 Cole Boulevard, Golden, Colorado 80401-3393 303-275-3000 • www.nrel.gov

Operated for the U.S. Department of Energy Office of Energy Efficiency and Renewable Energy by Midwest Research Institute $\cdot$ Battelle

\section{NREL/FS-500-39953 • May 2006}

Printed with a renewable-source ink on paper containing at least $50 \%$ wastepaper, including $10 \%$ post consumer waste. 